\title{
OS SENTIDOS DE NAÇÃO EM CAPÍTULOS DE HISTÓRIA COLONIAL: POR UMA ANÁLISE SEMÂNTICA DO TEXTO
}

\author{
MEANINGS OF NAÇÃO IN CAPÍTULOS DE HISTÓRIA COLONIAL: FOR A SEMANTIC ANALYSIS OF A \\ TEXT
}

\section{LOS SENTIDOS DE NACIÓN EN CAPÍTULOS DE HISTORIA COLONIAL: POR UN ANÁLISIS SEMÁNTICO DEL TEXTO}

\author{
Jefferson Voss ${ }^{1}$ \\ Universidade Estadual de Campinas - UNICAMP, Campinas, BR
}

\begin{abstract}
RESUMO: O presente texto tenciona apresentar uma breve análise dos sentidos do sintagma nação (e de seu plural, nações) no livro Capítulos de História Colonial, de Capistrano de Abreu. Para tanto, recorremos à Semântica do Acontecimento teorizada por Guimarães (2002) e, mais particularmente, à proposta de análise textual-semântica atualmente desenvolvida pelo mesmo autor (GUIMARÃES, 2011). O intuito é o de mostrar como se pode fazer a análise semântica de um sintagma a partir das diversas relações de integração entre tal sintagma, os enunciados em que aparece e o texto como um todo. O resultado da análise mostra como a relação entre o presente da enunciação e os movimentos de reescrituração incide na substituição de Brasil por nação ao longo do texto de Capistrano de Abreu.

PALAVRAS-CHAVE: análise semântica de texto; identidade nacional; história colonial.
\end{abstract}

ABSTRACT: This text aims at presenting a brief analysis of the meanings of the phrases nação and nações (nation, from Portuguese, and its plural form, nations) in the book Capítulos de História Colonial, by Capistrano de Abreu. In order to get to the results, our analysis was based on the Semantics of the Events developed by Guimarães (2002) and the Semantic Analysis of Texts, currently proposed by the same author (GUIMARÃES, 2011). Our main objective is to show how it is possible to make a semantic analysis of a phrase from the various relationships of integration among such phrase, utterances in which it appears and the text as a whole. The result of the analysis show the way the relationship between the present time of enunciation and the movements of rewriting focus on replacing Brasil for nação in the text by Capistrano de Abreu.

KEYWORDS: semantic analysis of texts; national identity; história colonial.

RESUMEN: El presente texto se propone presentar un breve análisis de los sentidos del sintagma nación (y de su plural, naciones) en el libro Capítulos de Historia Colonial, de Capistrano de Abreu. Para eso, se recurre a la Semántica del Acontecimiento teorizada por Guimarães (2002) y, especialmente, a la proposición de análisis textual-semántico actualmente desarrollada por ese mismo autor (GUIMARÃES, 2011). El propósito del trabajo es mostrar cómo se puede hacer un análisis semántico de un sintagma a partir de distintas relaciones de integración entre este sintagma, los enunciados en los que aparecen y el texto como un todo. El resultado del análisis muestra cómo la relación entre el presente de la enunciación y los movimientos de reescritura inciden en la sustitución de Brasil por nación a lo largo del texto de Capistrano de Abreu.

PALABRAS-CLAVE: análisis semántico del texto; identidad nacional; historia colonial.

\section{INTRODUÇÃO}

Levando em conta algumas publicações mais recentes de Guimarães (2010 e 2011) e a articulação que o autor propõe entre procedimentos de análise semântica e procedimentos de análise textual, este artigo tem por objetivo analisar o funcionamento do sintagma nação (e seu plural nações) nos Capítulos de História Colonial, de Capistrano de Abreu.

Nosso interesse por essa análise se justifica, principalmente, por dois pontos: 1) a importância histórica dos Capítulos de História Colonial, como um texto que empreende uma descrição da colonização do Brasil entre os séculos XVI e XIX, de modo a mostrar certa evolução histórica do Brasil durante este período; 2) a relevância de se entender o funcionamento da cena enunciativa que determina os sentidos de nação no texto e que, por isso, condiciona um certo modo de se contar a história do Brasil sob determinada enunciação em um acontecimento. Ou seja, entendemos que analisar o sentido de nação no texto de Capistrano possa nos

${ }^{1}$ Mestre em Letras pela Universidade Estadual de Maringá e Doutorando em Linguística pelo Instituto de Estudos da Linguagem da Universidade Estadual de Campinas. Bolsista de Doutorado do CNPq, processo 151107/2011-4. E-mail: jeffersonvoss@yahoo.com.br. 
servir para entender os lugares de enunciação que, em hipótese, denunciam as relações de pertencimento e a construção de uma identidade nacional, ou não.

O procedimento analítico de Guimarães (2010 e 2011) é de muita valia na medida em que permite analisar os sentidos de uma expressão na articulação entre essa expressão e os enunciados que integram o texto. Iniciamos nossa discussão com uma breve exposição desse procedimento e então passamos para a análise dos Capítulos de História Colonial.

\section{PROCEDIMENTO DE ANÁLISE SEMÂNTICA DO TEXTO}

Dado que tomaremos para análise os Capítulos de História Colonial (doravante, CHC), de Capistrano de Abreu, e já pressupomos, de antemão, que tal obra será tratada como um texto, cabe nos posicionarmos sobre a concepção de texto que adotamos a fim de analisar a obra e sobre o dispositivo teórico de análise do texto do qual nos valemos para a análise semântica do sintagma nação nos CHC. Uma questão prioritariamente se impõe: como analisar um texto do ponto de vista semântico e, então, não se restringir à análise de palavras, sintagmas curtos ou enunciados?

O começo da resposta vem como uma constatação à primeira vista simples: o texto faz sentido. Ora, se o texto faz sentido, é porque é mantido por relações de sentido entre fonemas, morfemas, lexemas, sintagmas e enunciados. Guimarães (2010) toma de Benveniste a noção de integração para pensar no modo como, no caso do texto, essa relação é uma relação transversal de integração de enunciados no texto, fazendo com que o mesmo signifique. Desenvolvendo a noção de integração de Benveniste (1988), segundo a qual um elemento sempre se integra a outro elemento para a produção de um elemento de nível superior2 (ex.: dois fonemas integrados em um morfema), Guimarães (2010) irá, para a análise do texto, transpor a segmentalidade subentendida às relações integrativas e pensará a integração de enunciados em tex to como um fenômeno transversal que atravessa todo o corpo do texto na produção de sentidos. É desse modo que, para Guimarães, o texto produz sentido por meio das relações entre os enunciados que o integram, da mesma forma que as palavras e os enunciados do texto só terão sentido na relação transversal de integração que eles têm com o texto ao qual estão integrados. Nas palavras do autor:

A relação de integração é aquela que constitui sentido, ela se caracteriza por ser uma relação de um elemento lingüístico de um nível com um elemento de nível superior. E não se trata de uma relação caracterizada pela segmentalidade. A integração se faz por uma relação transversal entre elementos diversos e a unidade à qual se reportam. A relação entre os elementos não é de contiguidade, não se marca pela direção da segmentalidade. (GUIMARÃES, 2011, p. 43).

O texto é, para Guimarães (2010, p. 22), “[...] uma unidade de sentido integrada por enunciados. Ou seja, um texto não é um conjunto de enunciados, nem é uma unidade composta de enunciados", na medida em que é a integração entre os elementos que o compõem que define seus sentidos, numa relação não segmental. Sendo assim, tanto as palavras quando os enunciados têm seus sentidos determinados pelas relações de integração dos enunciados no texto: o sentido será estabelecido pela relação entre um elemento X1 e uma unidade superior T. X1 integra T e é justamente por isso que significa; é essa relação de integração que produz o sentido de X, elemento de nível inferior a T. Dessa forma, a relação de integração é a relação transversal que produz sentido.

Desse ponto de vista, em que o sentido pode ser constatado para além da dimensão do enunciado, uma teoria semântica não trabalhará como a semântica formal de Frege, por exemplo, segundo a qual, através do sentido, é possível a verificação da referência, sendo o sentido o modo de apresentar a referência e a descrição do objeto a que se refere. Também não adotará o ponto de vista de uma pragmática como a de

2 "Pelo fato de serem discretas, as entidades lingüísticas admitem duas espécies de relação: entre elementos de mesmo nível ou entre elementos de níveis diferentes. Essas relações devem ser bem distinguidas. Entre os elementos de mesmo nível, as relações são distribucionais; entre elementos de nível diferente, são integrativas” (BENVENISTE, 1988, p. 83, grifos do original). 
Grice, para a qual a significação se estabelece entre o falante e sua intenção e a linguagem é mero instrumento pelo qual o falante formula sua intenção. Guimarães (2002) desenvolverá a Semântica do Acontecimento para relacionar a produção de sentido ao acontecimento da enunciação e sua temporalidade específica. Segundo o autor,

A temporalidade do acontecimento constitui seu presente e um depois que abre o lugar dos sentidos, e um passado que não é lembrança ou recordação pessoal de fatos anteriores. O passado é, no acontecimento, rememoração de enunciações, ou seja, se dá como parte de uma nova temporalização, tal como a latência de futuro. É nesta medida que o acontecimento é diferença na sua própria ordem: o acontecimento é sempre uma nova temporalização, um novo espaço de conviviabilidade de tempos, sem a qual não há sentido, não há acontecimento de linguagem, não há enunciação. (GUIMARÃES, 2002, p. 12).

A integração de enunciados ao texto deve ser pensada, então, a partir do acontecimento da enunciação que a estabelece. Ligando essas discussões teóricas, sobre o acontecimento da enunciação e a relação de integração de enunciados em textos, é que Guimarães, em um dos seus últimos trabalhos, nos dará uma concepção mais completa de texto: "O texto é uma unidade de sentido que integra enunciados no acontecimento da enunciação" (2011, p. 19). Portanto, na análise do texto, devem ser levados em conta o acontecimento que consubstancia a enunciação e a cena enunciativa que distribui os lugares de enunciação no acontecimento.

Uma palavra, em um texto, tem então seu sentido determinado por sua integração a um enunciado e, muito mais que isso, pela integração dos enunciados no texto. Isso quer dizer que uma teoria semântica baseada nessa concepção de texto tomará o texto como a principal unidade de sentido que define a significação de elementos de nível inferior, como os enunciados e as palavras ou expressões. No caso de nossa análise, isso implica a tomada do texto (os CHC) como referência principal para a análise da palavra nação, já que se entende que os sentidos desse sintagma serão definidos pelas relações de integração entre ele e os enunciados do qual faz parte e entre esses enunciados e o texto.

Guimarães (2011) alerta que não se trata, todavia, de uma semântica do texto, já que o nível máximo para a análise semântica ainda será o do enunciado. Contudo, na análise da produção de sentidos pelo enunciado, será condição entender que o enunciado só produz sentidos na sua integração ao tex to no acontecimento da enunciação:

[...] consideramos que a unidade de análise semântica é o enunciado. E consideramos que o enunciado é o um elemento lingüístico que integra texto. Ou seja, para que um certo tipo de sequência linguística seja enunciado é necessário que integre texto. Como se vê, deste ponto de vista, o próprio modo de conceber a tarefa da semântica leva a uma certa concepção de texto. (GUIMARÃES, 2011, p. 43).

Tomamos como tarefa, então, entender os sentidos da expressão nação (e seu plural nações) nos CHC de Capistrano de Abreu, na tentativa de mostrar como esses sentidos estão articulados ao modo como os enunciados integram o texto como um todo.

\section{OS SENTIDOS DE NAÇÃo EM CAPÍTULOS DE HISTÓRIA COLONIAL}

O livro Capítulos de História Colonial, de João Capistrano de Abreu, empreende uma descrição da colonização do Brasil entre os séculos XVI e XIX de modo a mostrar certa evolução histórica do Brasil durante este período. A obra focaliza tanto aspectos geográficos e políticos da formação do Brasil colônia, como as guerras por território, a delimitação das fronteiras e os interesses por matéria-prima oferecida pelo Novo Mundo, quanto fatores sócio-culturais, como modos de vida dos colonizadores, miscigenação racial, estratificação social, entre outros. O texto está dividido em onze capítulos: o primeiro capítulo traz uma descrição da dimensão geográfica do Brasil e de sua fauna e flora e também algumas considerações sobre o indígena brasileiro; o capítulo segundo é uma descrição das relações hierárquicas na Coroa Portuguesa e do perfil do português; do capítulo terceiro ao nono, há uma narrativa que atravessa desde o descobrimento até o povoamento do sertão brasileiro; o capítulo dez de certa forma retorna ao capítulo primeiro e explica 
como os limites do Brasil chegaram a ser o que são; e o último capítulo traz um panorama geral sobre a distribuição étnica da população brasileira já no século XIX e sobre seus costumes.

Em termos quantitativos, a expressão nação aparece 21 (vinte e uma) vezes nos CHC: 11 (onze) vezes no singular (nação) e 10 (dez) vezes no plural (nações).

A primeira ocorrência de nação no texto se dá já no primeiro capítulo e segundo parágrafo da obra. Capistrano fala, então, dos limites territoriais do Brasil: "Cercam-no [o Brasil] ao Sul, a Sudoeste, Oeste e Noroeste as nações castelhanas do continente, exceto o Chile, por se interpor a Bolívia, e o Panamá por se interpor a Colômbia" (To1)3 (p. 43). Como se nota, a divisão política descrita pelo autor para localizar o Brasil já é do final do século XIX e começo do século XX (o presente da enunciação) e não aquela do Brasil colônia, foco do restante do texto. Dessa forma, o sentido de nação já é determinado, por uma relação parafrástica subtendida por Chile, Bolívia, Panamá e Colômbia (enquanto países com divisões políticas e territoriais já definidas, quando Capistrano escreve o livro). Note-se também que a especificação dada a nações (castelhanas) é regrada pela língua falada nos países citados - o que inscreve o fator língua como um fator que diferencia de certa forma uma nação da outra.

Não podemos ignorar, contudo, o primeiro parágrafo, anterior a esse segundo, em que Brasil é reescrito por país: "A quase totalidade do Brasil demora no hemisfério meridional, e entre o Equador e o trópico de Capricórnio alcança o país as maiores dimensões” (To2) (p. 43). A temporalidade do acontecimento da cena enunciativa é a do presente da enunciação, em que Capistrano, enquanto locutor, assume o tempo da enunciação como sendo o século XIX, época em que escreveu os CHC. Logo, o sentido de nação de certa forma reescreve por substituição o sentido de país, dado que as especificações para as duas expressões são as mesmas: limites políticos e territoriais do século XX (para país temos Brasil; para nações temos Chile, Bolívia, Panamá e Colômbia).

Na continuação do segundo parágrafo (To1), Capistrano diz: "Desde o alto rio Branco até beira-mar seguem-se colônias de Inglaterra, Holanda e França, ao Norte” (To3) (p. 43). Há, nesse trecho, uma segunda especificação para nação: o fato de não ser colônia (não-colônia). Nesse caso, nação assume o sentido de livre, não-alienado, com poderes próprios. As colônias não são, como se vê, nomeadas por Capistrano, o que ele nomeia são as respectivas nações/países metrópoles das colônias. Sabendo-se que o Brasil e os demais países da América Latina nunca foram metrópoles de colônias, vemos que o sentido de nação não tem a ver diretamente com o sentido de metrópole, mas com o de não-colônia. A partir do momento em que as colônias não são determinadas com um nome próprio, há uma valoração de nação/país em relação às colônias, no sentido de que a nação é aquela que merece ser nomeada/determinada por um nome próprio (Inglaterra, Holanda e França).

Dessa breve reflexão, podemos depreender o seguinte esquema:

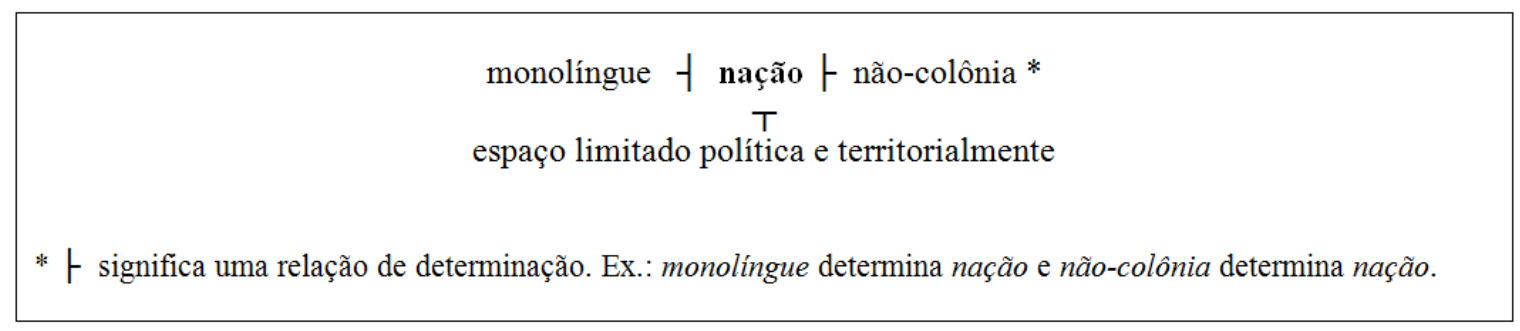

Quadro 1: Sentidos de nação no primeiro capítulo dos CHC.

s A fim de facilitar a leitura, numeraremos os recortes extraídos do texto em análise: To1 equivalerá a Trecho 01. 
Outra ocorrência de nação, a segunda delas inclusive, se dá no segundo capítulo, Fatores Exóticos, em que Capistrano fala da formação do povo brasileiro fazendo referência ao estereótipo do homem português da época do descobrimento e também ao perfil do negro trazido ao Brasil. Na passagem, o autor trata especificamente das divisões hierárquicas do povo português:

\begin{abstract}
Abaixo da nobreza acampava o povo, a grande massa da nação, sem direitos pessoais, apenas defendidos seus filhos por pessoas morais a que se acostavam, lavradores, mecânicos, mercadores; os de mor qualidade chamavam-se homens bons, e reuniam-se em câmaras municipais, órgãos de administração local, cuja importância, então e sempre somenos, nunca pesou decisivamente em lances momentosos, nem no Reino, nem aqui […]. (To4) (p. 57).
\end{abstract}

Nesse recorte, nação é determinado por povo e nobreza, sendo que povo equivale ao que seria a grande massa da nação, ou seja, a maior parte da nação. Nação é, então, de certa forma reescrito por pessoas, habitantes. Juntando esse recorte com os anteriores, poderíamos chegar ao seguinte enunciado: "Nação é o conjunto de pessoas (nobreza e povo) que compartilham a mesma língua em um território independente". Pareceria fácil, até aqui caracterizar o sentido de nação nos CHC. Contudo, alguns problemas podem ser encontrados.

O primeiro deles se refere ao caráter descritivo do primeiro capítulo, escrito prioritariamente no presente factual (presente do indicativo), em contraposição ao caráter narrativo do segundo capítulo, escrito nas formas perfeitas e imperfeitas do pretérito. Isso nos dá a chave para crer que a descrição feita no capítulo primeiro se refere ao presente da enunciação, ou seja, o estado em que o Brasil se encontrava em termos de divisão política no final do século XIX. Justamente por isso, nação no primeiro capítulo será uma reescrituração de país e condensará os sentidos de Bolívia, Chile, Colômbia, etc. e inclusive Brasil. Isto significa que, no primeiro capítulo, o Brasil é caracterizado como nação e a nação se juntam todos os elementos do Quadro 01: tem limites territoriais definidos, fala uma língua em particular e não é uma colônia.

A partir do capítulo segundo, entretanto, Capistrano se vale de um tom narrativo para contar a história do Brasil, o que implica uma mudança na cena enunciativa e no lugar social que o próprio locutor ocupa. Não se trata de se valer do tempo presente para descrever a situação em que o Brasil se encontrava no final do século XIX, mas de retornar ao passado para narrar tudo o que Brasil viveu entre 1500 e 1800 , durante o período em que foi colônia de Portugal.

Isso já é bem sintomático em relação ao sentido que nação passará a ter a partir do segundo capítulo. Tendo em vista que Capistrano tratará do Brasil-colônia e o sentido de nação já é dado de antemão como o de nãocolônia, a partir do capítulo dois o Brasil não será mais tratado como nação, pois o acontecimento da enunciação (a imersão histórica a que o locutor se propõe) o obriga a dissimular o tempo passado e condicionar o sintagma Brasil a uma temporalidade diferente daquela vivida pelo locutor: é um efeito direto da posição de historiador na qual o locutor se encontra.

Entre os capítulos dois e nove, capítulos que essencialmente discorrem sobre a colonização do litoral brasileiro e a disputa de território com Holanda, França e Espanha, a expressão nação servirá apenas para caracterizar metrópoles já formadas - os colonizadores. O trecho a seguir é um exemplo:

A presença dos intrusos prejudicava-os [os portugueses] a todos os respeitos: nos mercados europeus, oferecendo os gêneros a preços mais vantajosos, pois não tinham quintos a deduzir, e levando-os diretamente aos mercados consumidores, pois não eram obrigados a parar em Lisboa; nas terras brasílicas, conciliando as simpatias dos naturais, que os agasalhariam com maior carinho, poupar-lhesiam traições e aleives, dariam preferência nos carregamentos e se habituariam às mercadorias francesas. Ainda por cima havia a questão de princípio: Portugal não admitia que os filhos de outra nação pusessem o pé em terras suas no além-mar. (TO5) (p. 73).

Esse trecho, além de mostrar como o sentido de nação se refere ao que é exterior às colônias, ainda serve para que identifiquemos um outro traço de nação: a questão da gênese. É um acréscimo ao que até aqui 
havíamos caracterizado como nação. Da expressão "filhos de outra nação", subentende-se que a nação tenha filhos, ou seja, a nação é formada por aqueles que nela nascem. Um possível enunciado dado a partir dessa constatação seria: "Nação é o conjunto de pessoas (nobreza e povo) que compartilham a mesma língua em um território independente e que mantém entre si relações genealógicas”.

A questão da exterioridade da metrópole em relação à colônia permanece do segundo ao nono capítulo. Entre estes capítulos, nação serve para designar estados colonizadores exteriores ao Brasil. Em nenhum momento o sintagma reescritura o Brasil ou o povo brasileiro. Esse traço atribuído a nação (o de nãocolônia) se confirma na primeira ocorrência em que nação volta a ter relação com o sintagma Brasil. Esta se dará no capítulo nono, O Sertão, e aparece em uma citação de Francisco Xavier de Mendonça Furtado em discurso direto: "E estes são os homens de quem se diz não têm juízo nem são capazes de nada! Deles se pode fazer uma nação como qualquer outra de que se pode tirar grande interesse" (T06) (p. 208). O trecho diz respeito à liberdade dos índios e Francisco Xavier comenta como dos índios também se poderia formar uma nação.

Como se vê, não há uma relação de reescrituração efetiva de Brasil por nação. Ao contrário, diz-se de um elemento do Brasil do qual se poderia fazer uma nação, o indígena. Desse modo, Brasil ainda não é reescriturado por nação e mantém na narrativa sua condição de colônia. A diferença, durante o texto, é que nação passa então a caracterizar uma possibilidade de designação para o indígena brasileiro (e não para o povo brasileiro) e, principalmente, nação passa a se relacionar com o conceito de povo livre.

Outro trecho em que nação reescreve povos indígenas aparece também no nono capítulo. Novamente se trata de uma citação em discurso direto, dessa vez do Frei Domingos Teixeira: "Depois de dar em larga relação notícia exata dos sertões que penetrou, rios, e nações várias que os habitam, sinalando pelos graus as alturas do polo, mais gasto do trabalho, que dos anos, veio a acabar [João Velho do Vale] em benefício da pátria, com serviços maiores que a gratidão" (To7) (p. 164). Nesse novo trecho, ficam claras as relações de sentido entre nação e liberdade. $\mathrm{O}$ trecho narra uma viagem ao sertão ainda não desbravado e a localização, neste, de nações indígenas, vivendo em liberdade, sem contato com os colonizadores. Em comparação a To6, temos que um povo indígena só é caracterizado enquanto nação quando está liberto. A partir do momento que perde sua liberdade ele não mais configura uma nação - tanto que em To6 fala-se de dar liberdade aos índios e, então, permitir que deles se "faça uma nação". Ou seja, povos indígenas reescreve nação quando a ele se acrescenta o traço de liberto (não-escravizado).

A colônia, nos CHC, não possui o sentido de nação. Ao contrário, nação é aquela que tem o direito de possuir uma colônia, dado seu estado de liberdade. O seguinte recorte mostra claramente essa questão de posse: "Pretextou para esta violência, estar divulgado nele o segredo do Brasil aos estrangeiros. Não se vê bem como podia fazê-lo: cultiva-se cana e fabricava-se açúcar em colônias de outras nações; plantava-se também fumo, criava-se gado, trafegavam-se minas" (To8) (p. 205). O sentido de nação se vê atrelado ao fato de um povo possuir ou não liberdade.

Depois das duas ocorrências (To6 e To7) em que nação reescritura de alguma forma povos indígenas, o restante das passagens em que nação aparece apenas relaciona a expressão a estados europeus já formados e colonizadores, como Portugal e Espanha. Em nenhum momento, nos últimos capítulos do livro, nação aparece para reescriturar Brasil.

Tudo bem que isso seja justificável dada a posição de historiador que o locutor ocupa. Essa posição o obriga a condicionar o Brasil ao estatuto que o mesmo possuía na temporalidade específica da narrativa, entre os séculos XVI e XIX, antes da República. Contudo, se no começo de nossa análise, ao falar do capítulo primeiro dos CHC, apontamos alguma relação sinonímica entre nação e país, no sentido de que possuiriam os mesmos traços constituintes, isso não se aplica ao restante da obra. 
Mesmo nos capítulos narrativos dos CHC, em que o Brasil é colônia, país reescritura Brasil por mais de uma vez, o que distingue país de nação. Isso indica que, no texto, nação possui algum traço semântico específico que não permite considerar o Brasil como nação, o que, com efeito, pode ser realizado no caso de país - o Brasil-colônia é um país, mas não é uma nação.

Do ponto de vista político e territorial, sabemos que, na posição de historiador do locutor, Brasil também não deveria, a princípio, ser reescrito por país, já que não se tratava, no período colonial, de um Estado livre com sistema e divisões políticos próprios. Mas o que nos desperta curiosidade é justamente haver essa possibilidade de designação no acontecimento da enunciação e, mais que isso, não haver a possibilidade da reescrituração de Brasil como nação. Ou seja, se inicialmente pudemos dizer que tanto nação quanto país são um "conjunto de pessoas (nobreza e povo) que compartilham a mesma língua em um território independente (livre) e que mantém entre si relações genealógicas”, agora já não o podemos mais.

Nação, nos CHC, parece estar impregnado de algo relacionado a uma identidade nacional já constituída e reforçada. Enquanto país pode designar mesmo uma colônia, território mais ou menos recortado e administrado por uma metrópole, nação só designa, conforme Capistrano, um povo muito bem definido por suas raízes identitárias. Caso bem marcante é o dos indígenas: enquanto vivem em suas tribos de forma bem estruturada (com seus costumes e valores) e livres, são caracterizados como nação. A partir do momento em que perdem a liberdade e passam a viver entre os brancos colonizadores também perdem o estatuto de nação. A possibilidade para que constituam outra nação só se dá quando adquirem a liberdade e voltam a se organizar cultural e politicamente, mesmo que, desta vez, entre aqueles que os escravizaram.

\section{CONSIDERAÇÕES FINAIS}

Chegamos ao final de nosso texto sentindo certa coerção para que voltemos a seu início, quando discutíamos a relação entre análise de texto e o trabalho do semanticista. Perguntamo-nos o que era texto e respondemos com base nas discussões de Guimarães. A partir daquela discussão é que nos empenhamos na análise para que o tratamento semântico dado ao sintagma nação nos permitisse uma análise do texto em si, dos CHC de Capistrano de Abreu. E imaginamos que o resultado tenha sido produtivo.

Como pudemos ver, o tratamento de um sintagma em relação ao enunciado e do enunciado em relação aos outros enunciados que integram o texto garante que a análise semântica ultrapasse o próprio nível do enunciado e proporcione um gesto interpretativo do texto. Nos $\mathrm{CHC}$, por exemplo, isso nos permite enxergar que nação responde a duas injunções temporais que dividem o acontecimento da enunciação entre o tempo da narração e o tempo da enunciação - o que faz com que as relações de designação se transformem, como no caso entre Brasil e nação.

Não objetivamos necessariamente esgotar a interpretação da obra analisada, já que entendemos que o papel do semanticista e do estudioso dos discursos seja o de produzir gestos de leitura que explorem os efeitos de sentido que um texto produz para uma comunidade de leitores. Mas também entendemos que é justamente isso que torna interessante o procedimento analítico que aqui aplicamos: ele também permite que nos reposicionemos como leitores mais aguçados quando da leitura de um texto, já que algumas idas e vindas são necessárias para que se chegue a alguma conclusão sobre o texto analisado e sobre o modo como o tex to agencia os sentidos das palavras e expressões de uma língua

\section{REFERÊNCIAS}

ABREU, J. C. Capítulos de História Colonial, 1500-1800. 7. Ed. revisada, anotada e prefaciada por José Honório Rodrigues. Belo Horizonte; Itatiaia: Editora Universidade Itatiaia Limitada; São Paulo: Editora da Universidade Estadual de São Paulo, 1988.

BENVENISTE, E. Os níveis da análise linguística. In: Campinas: Pontes; Editora da Unicamp, 1988. p. 127-140. Problemas de linguística geral I. 2. ed. 
GUIMARÃES, E. Semântica do acontecimento: um estudo enunciativo da designação. Campinas: Pontes, 2002.

Quando o Eu se diz Ele: análise enunciativa de um texto de publicidade. Revista da Anpoll, n. 29, jun. 2010 .

Análise do texto: procedimentos, análises, ensino. Campinas: Editora RG, 2011.

Recebido em 26/04/12. Aprovado em 11/06/12. 